\title{
Endothelial-smooth muscle cell interactions in the regulation of vascular tone in skeletal muscle
}

\author{
Kim A Dora
}

Department of Pharmacology, University of Oxford, Mansfield Road, Oxford, OX1 3QT, UK

This work was supported by the British Heart Foundation (BHF) [grant numbers FS/08/033/25111, FS/13/16/30199, and IG/13/5/30431], and the Oxford BHF Centre of Research Excellence, RE/13/1/30181. KAD is a BHF-funded Senior Basic Science Research Fellow.

Short Title: Local and conducted dilation

Keywords: $\quad$ Conducted dilation

Cremaster

Electrical coupling

K ATP channel

$\mathrm{K}_{\mathrm{Ca}}$ channel

$\mathrm{K}_{\mathrm{IR}}$ channel

Corresponding author: Professor Kim Dora

Department of Pharmacology

University of Oxford

Mansfield Road

Oxford OX1 3QT

UK

Tel: +44-1865-281114

Fax: +44-1865-271853

kim.dora@pharm.ox.ac.uk 


\section{Abstract}

The smooth muscle cells (SMCs) of skeletal muscle arterioles are intricately sensitive to changes in membrane potential. Upon increasing luminal pressure, the SMCs depolarize, thereby opening voltage-dependent $\mathrm{Ca}^{2+}$ channels (VDCCs), which leads to contraction. Mechanisms that oppose this myogenic tone can involve voltagedependent and independent dilator pathways, and can be endothelium-dependent or independent. Of particular interest are the pathways leading to hyperpolarization of SMCs, as these can potentially evoke both local and conducted dilation. This review focuses on three agonists that cause local and conducted dilation in skeletal muscle: acetylcholine (ACh), adenosine triphosphate (ATP) and $\mathrm{KCl}$. The mechanisms for the release of these agonists during motor nerve stimulation and/or hypoxia, and their actions to open either $\mathrm{Ca}^{2+}$-activated $\mathrm{K}^{+}$channels $\left(\mathrm{K}_{\mathrm{Ca}}\right)$ or inwardly rectifying $\mathrm{K}^{+}$ channels $\left(K_{\mathbb{R}}\right)$ are described. By causing local and conducted dilation, each agonist has the ability to improve skeletal muscle blood flow during exercise and ischemia. 


\section{Introduction}

The myogenic tone observed in skeletal muscle arterioles occurs secondary to depolarization and an increase in the open-probability of voltage-dependent $\mathrm{Ca}^{2+}$ channels (VDCCs) [1]. This tone is sensitive to nifedipine, reflecting a major contribution by L-type VDCCs [1-3]. The mechanism for depolarization is not fully understood, but possible candidates are cation influx through stretch-activated channels [4], and transient receptor potential (TRP) channels [5]; and $\mathrm{Ca}^{2+}$-activated channels, including TRPM4, TRPC6 and $\mathrm{Cl}^{-}$channels [6]. How these are influenced by structural proteins, which can act as both mechano 'sensors' and 'transducers' [7, 8], has yet to be fully resolved. Together with locally-released and circulating vasoconstrictors, the intrinsic tone in skeletal muscle vascular beds at rest is high [9].

During ischemia, including that observed at the onset of exercise, blood flow markedly increases to satiate metabolic demand [9]. The mechanisms for selectively improving flow to these regions are many-fold. This review will focus on the factors locally released in response to metabolic demand, which act ultimately to hyperpolarize smooth muscle cells (SMCs). This is of particular interest as this hyperpolarization can not only stimulate dilation by reducing the open-probability of VDCCs within the area of ischaemia (local dilation) but can also signal bidirectionally through the wall of the arteries and arterioles to cause conducted dilation. Conducted dilation significantly reduces vascular resistance to increase blood flow with sufficient magnitude to match flow and metabolic demand [10-15]. It relies on the passage of current through gap junctions, often including a role for myoendothelial gap junctions, using the endothelium as the conduit [16-24, reviewed in 25] (Figure 1), and does not require further opening of $\mathrm{K}^{+}$channels at the upstream sites. In most cases conducted dilation is not altered in the presence of a nitric oxide synthase inhibitor [18, 25, 26]. 


\section{Factors influencing blood flow in the cremaster microcirculation}

The arteries and arterioles within skeletal muscle preparations used for intravital microscopy, such as the cremaster muscle, dilate following a reduction in $\mathrm{pO}_{2}$ or stimulation of skeletal muscle bundles [27-31]. Three examples of vasodilator mediators that could contribute to this dilation are the focus of this review. They include acetylcholine $(\mathrm{ACh})$ released from depolarized motor nerve endplates [32]; adenosine triphosphate (ATP) released from hypoxic erythrocytes within the ischemic regions [33]; and the $\mathrm{K}^{+}$efflux occurring during repolarization of skeletal muscle fibres that acts to hyperpolarize adjacent SMCs [34, 35] (Figure 2).

\section{A role for acetylcholine $(\mathrm{ACh})$ ?}

Each skeletal muscle fibre is innervated by a motor nerve, releasing ACh as the neuromuscular transmitter. The pattern of innervation has been characterized within various preparations, including hamster cremaster muscle [36], and the proposal that ACh can spillover to reach capillaries and arterioles functionally has been demonstrated in vivo [32]. Not only does stimulation of skeletal muscle fibres evoke a vasodilatation dependent upon stimulus train duration within the vicinity of neuromuscular junctions (NMJs), but dilation occurs also upstream. The dilation at the upstream site was not dependent on muscarinic receptors whereas local dilation was, suggesting an important role for a 'spillover' action of ACh directly to activate endothelial cell (EC) muscarinic receptors and to further affect blood flow, conducted dilation upstream beyond the spillover site [32]. Importantly from a metabolic point of view, this is separate to the action of $\mathrm{ACh}$ at nicotinic receptors in the $\mathrm{NMJ}$, as experiments were performed in the presence of tubocurarine to prevent skeletal muscle contraction. The endogenous source of $\mathrm{ACh}$ could also reflect release from non-neuronal sources such as ECs themselves as the machinery for making and releasing ACh exists within ECs [37]. How this links to release during increased metabolic demand is not yet known. In 
various rodent models for intravital microscopy and sharp microelectrode recordings, it has been shown that focally-applied ACh can stimulate both local and conducted hyperpolarization and dilation [38], responses that are associated with and dependent on increases in $\mathrm{EC} \mathrm{Ca}^{2+}$ at the site of stimulation $[39,40]$.

When studied in isolation and under luminal pressure, ACh stimulates an increase in EC $\mathrm{Ca}^{2+}$, hyperpolarization and dilation of rat cremaster arterioles, a response underpinned by opening all three subtypes of $\mathrm{Ca}^{2+}$-activated $\mathrm{K}^{+}\left(\mathrm{K}_{\mathrm{Ca}}\right)$ channels: small (S), intermediate (I) and large (B) conductance, sensitive to apamin, TRAM-34, and iberiotoxin, respectively $[1,24,26,40]$. In cremaster arterioles, both $\mathrm{SK}_{\mathrm{Ca}}$ and $\mathrm{IK}_{\mathrm{Ca}}$ channels are present in endothelial cells (ECs) whereas $\mathrm{BK}_{\mathrm{Ca}}$ channels are present in at least SMCs [41-44]. It has also been shown that a similar profile of hyperpolarization is observed in vivo, as shown following either genetic deletion or pharmacological blockade $[22,45,46]$. Therefore with each cycle of skeletal muscle contraction, ACh can potentially act locally at EC muscarinic receptors to stimulate local and conducted dilation. Whether $\mathrm{ACh}$ is similarly released from non-neuronal sources during ischaemia has yet to be defined.

\section{A role for adenosine triphosphate (ATP)?}

The concentration of extracellular ATP increases when erythrocytes are made hypoxic, and can act at EC purinergic $\mathrm{P} 2 \mathrm{X}$ and $\mathrm{P} 2 \mathrm{Y}$ receptors to stimulate dilation $[18,26,33$, 47, 48]. When luminally applied to arterioles, ATP stimulates both local and conducted dilation both in vivo [40,49] and in isolated cremaster arterioles [26]. In this context ATP can act via $\mathrm{G}_{\mathrm{q} / 11}$-coupled $\mathrm{P} 2 \mathrm{Y}_{1}$ receptors [26] although other receptors likely also play a role; and if broken down to adenosine, can potentially act at adenosine receptors [50]. The EC P2Y receptor responses are very similar in profile to that of ACh, acting via $\mathrm{K}_{\mathrm{Ca}}$ channels stimulated by increases in $\mathrm{EC} \mathrm{Ca}^{2+}[26,40]$. Therefore in 
situations of ischaemia, whether at rest or during exercise, the circulating erythrocytes can act as specialized shuttles for the release of ATP which then stimulates dilation and improves flow. When flow increases, potentially both the $\mathrm{pO}_{2}$ and velocity of flux increases, reducing both the stimulus for and accumulation of ATP. As with ACh, the sources of ATP can be many-fold, including neuronal and non-neuronal sources such as ECs [51-53], and interestingly there is evidence that ECs can release ATP in response to hypoxia [52]. How each source may or may not contribute to dilation requires further investigation.

\section{A role for $\mathrm{K}^{+}$?}

Small increases in the concentration of extracellular $\mathrm{K}^{+}$, up to $20 \mathrm{mM} \mathrm{KCl}$, stimulates hyperpolarization and dilation of skeletal muscle arterioles due to opening $\mathrm{K}_{\mathbb{I R}}$ channels and stimulation of the $\mathrm{Na}^{+} / \mathrm{K}^{+}$-ATPase $[24,26,54]$. $\mathrm{KCl}$ can also stimulate conducted dilation in skeletal muscle, shown with focally-applied $\mathrm{KCl}$ at various concentrations [26, 55,56 ] and by luminal perfusion [26]. When applied for short periods at $19 \mathrm{mM}, \mathrm{KCl}$ stimulated both local and conducted dilation via activation of $K_{\mathbb{R}}$ channels [26], a profile similar to that seen in the coronary microcirculation [57]. The actions of $\mathrm{KCl}$ are of relevance within skeletal muscle as $\mathrm{K}^{+}$can accumulate extracellularly during fibre contraction both from open voltage-gated $\mathrm{K}^{+}$channels in each repolarization phase, or via $\mathrm{K}_{\text {ATP }}$ channels when intracellular ATP levels decrease. $\mathrm{K}^{+}$channels in the vascular wall itself could also play a role, and indeed the accumulated $\mathrm{K}^{+}$acting at vascular $\mathrm{K}_{\mathrm{IR}}$ channels can act in an autocrine manner. Of interest with $\mathrm{K}_{\mathrm{IR}}$ channels is their property of being more likely to be open at hyperpolarized potentials, therefore $\mathrm{K}_{\mathrm{IR}}$ channels are more effective as membrane potential approaches the equilibrium potential [58] (calculated as $\sim-90 \mathrm{mV}$ ), helping to maintain hyperpolarization and dilator responses.

$\mathrm{K}_{\mathrm{IR}}$ channels are at least expressed in hamster cremaster arteriole smooth muscle cells [54], but their presence in ECs has not yet been established. However, the latter may 
provide the pathway for facilitating conducted dilation $[26,59]$. Thus, the action of $\mathrm{K}^{+}$ itself could signal from contracting skeletal muscle fibres to act on the vasculature, and then may also act by amplifying conducted dilation.

\section{Other vasodilators within the microcirculation}

$\mathrm{K}_{\mathrm{ATP}}$ channel openers such as pinacidil and cromakalim stimulate local and conducted dilation in hamster [29] and mouse [46, 60] cremaster preparations in vivo. Therefore, as ATP levels drop in SMCs where the channels are expressed [61], this pathway could be stimulated. Further to this, agonists acting through $\mathrm{G}_{\mathrm{s}}$-coupled receptors in SMCs can potentially activate $\mathrm{K}_{\mathrm{ATP}}$ channels via protein kinase $\mathrm{A}$ [62], including catecholamines, adenosine, prostacyclin, and calcitonin gene-related peptide, to similarly evoke local and conducted dilation. In endothelial cells agonists acting at $\mathrm{G}_{\mathrm{q} / 11}$-coupled receptors could act in a similar manner to ACh and ATP, including 5hydroxytryptamine, histamine, bradykinin, tachykinin, calcium-sensing, and proteinaseactivated receptors.

\section{Evidence in humans}

The ability of ACh, ATP and $\mathrm{K}^{+}$to act as autocrine and paracrine vasodilators is clear (Figure 2). When measured in the blood of humans the concentration of ACh and it's breakdown product choline were $<10 \mathrm{nM}$ and $>10 \mu \mathrm{M}$, respectively [63, 64]. This relatively high concentration of choline provides the tantalizing possibility that a nonneuronal cholingeric system yet to be resolved is important, and may involve blood components. When measured in humans, the plasma concentration of ATP is $\sim 1 \mu \mathrm{M}$ [65] and appears to play a role during exercise [51]; and the circulating levels of $\mathrm{K}^{+}$in plasma can increase by a few millimolar during exercise [66]. As in rodents, there is much evidence for vasodilator actions of each of these mediators, at least partly via the opening of $\mathrm{K}^{+}$channels $[34,67,68]$. Whether these mediators stimulate conducted 
dilation in human skeletal muscle has yet to be established, although there is some evidence for conducted dilation in human coronary arterioles [69].

In summary, a number of different mediators and ion channels have been implicated in the phenomenon of conducted dilation in skeletal muscle vascular beds. The contribution by each mediator to the amplitude and time course of an observed response remains to be established and represent areas of future important research.

\section{Acknowledgements}

Professor Chris J. Garland provided a useful critique of the manuscript. This work was supported by the British Heart Foundation (BHF) [grant numbers FS/08/033/25111, FS/13/16/30199, and IG/13/5/30431], and the Oxford BHF Centre of Research Excellence RE/13/1/30181. KAD is a BHF-funded Senior Basic Science Research Fellow.

\section{Conflict of interest}

There are no competing interests. 


\section{References}

1. Kotecha N, Hill MA, Myogenic contraction in rat skeletal muscle arterioles: Smooth muscle membrane potential and $\mathrm{Ca}^{2+}$ signaling. Am J Physiol Heart Circ Physiol 289: H1326-1334, 2005.

2. Hill MA, Meininger GA, Calcium entry and myogenic phenomena in skeletal muscle arterioles. Am J Physiol Heart Circ Physiol 267: H1085-H1092, 1994.

3. Potocnik SJ, Murphy TV, Kotecha N, Hill MA, Effects of mibefradil and nifedipine on arteriolar myogenic responsiveness and intracellular $\mathrm{Ca}^{2+}$. Br J Pharmacol 131: 1065-1072, 2000.

4. Wu X, Davis MJ, Characterization of stretch-activated cation current in coronary smooth muscle cells. Am J Physiol 280: H1751-1761, 2001.

5. Plant TD, TRPs in mechanosensing and volume regulation. Handb Exp Pharmacol 223: 743-766, 2014.

6. Bulley S et al., TMEM16A/ANO1 channels contribute to the myogenic response in cerebral arteries. Circ Res 111: 1027-1036, 2012.

7. Hill MA, Meininger GA, Arteriolar vascular smooth muscle cells: mechanotransducers in a complex environment. Int J Biochem Cell Biol 44: 1505$1510,2012$.

8. Gui P et al., Coordinated regulation of vascular $\mathrm{Ca} 2+$ and $\mathrm{K}+$ channels by integrin signaling. Adv Exp Med Biol 674: 69-79, 2010.

9. Segal SS, Integration and modulation of intercellular signaling underlying blood flow control. J Vasc Res 52: 136-157, 2015.

10. Segal SS, Jacobs TL, Role for endothelial cell conduction in ascending vasodilatation and exercise hyperaemia in hamster skeletal muscle. J Physiol 536: 937-946, 2001.

11. Segal SS, Regulation of blood flow in the microcirculation. Microcirc 12: 33-45, 2005. 
12. Duling BR, Berne RM, Propagated vasodilation in the microcirculation of the hamster cheek pouch. Circ Res 26: 163-170, 1970.

13. Williams DA, Segal SS, Feed artery role in blood flow control to rat hindlimb skeletal muscles. J Physiol 463: 631-646, 1993.

14. Kurjiaka DT, Segal SS, Conducted vasodilation elevates flow in arteriole networks of hamster striated muscle. Am J Physiol Heart Circ Physiol 269: H1723-H1728, 1995.

15. Dora KA, Damon DN, Duling BR, Microvascular dilation in response to occlusion: a coordinating role for conducted vasomotor responses. Am J Physiol Heart Circ Physiol 279: H279-284, 2000.

16. Yamamoto Y, Imaeda K, Suzuki H, Endothelium-dependent hyperpolarization and intercellular electrical coupling in guinea-pig mesenteric arterioles. J Physiol 514: 505-513, 1999.

17. Emerson GG, Segal SS, Endothelial cell pathway for conduction of hyperpolarization and vasodilation along hamster feed artery. Circ Res 86: 94-100, 2000.

18. Winter $P$, Dora KA, Spreading dilatation to luminal perfusion of ATP and UTP in rat isolated small mesenteric arteries. J Physiol 582: 335-347, 2007.

19. de Wit $\mathrm{C}$ et al., Impaired conduction of vasodilation along arterioles in connexin40deficient mice. Circ Res 86: 649-655, 2000.

20. Figueroa XF, Duling BR, Dissection of two Cx37-independent conducted vasodilator mechanisms by deletion of $\mathrm{Cx} 40$ : electrotonic versus regenerative conduction. Am J Physiol Heart Circ Physiol 295: H2001-2007, 2008.

21. Emerson GG, Segal SS, Electrical coupling between endothelial cells and smooth muscle cells in hamster feed arteries: role in vasomotor control. Circ Res 87: 474479, 2000. 
22. Hoepfl B, Rodenwaldt B, Pohl U, De Wit C, EDHF, but not NO or prostaglandins, is critical to evoke a conducted dilation upon ACh in hamster arterioles. Am J Physiol Heart Circ Physiol 283: H996-H1004., 2002.

23. Wölfle SE et al., Non-linear relationship between hyperpolarisation and relaxation enables long distance propagation of vasodilatation. J Physiol 589: 2607-2623, 2011.

24. McSherry IN et al., A role for heterocellular coupling and EETs in dilation of rat cremaster arteries. Microcirc 13: 119-130, 2006.

25. Domeier TL, Segal SS, Electromechanical and pharmacomechanical signalling pathways for conducted vasodilatation along endothelium of hamster feed arteries. J Physiol 579: 175-186, 2007.

26. Dora KA, Conducted dilatation to ATP and $\mathrm{K}^{+}$in rat skeletal muscle arterioles. Acta Physiol (Oxf) In Press, 2016.

27. Segal SS, Damon DN, Duling BR, Propagation of vasomotor responses coordinates arteriolar resistances. Am J Physiol Heart Circ Physiol 256: H832-H837, 1989.

28. Cohen KD, Berg BR, Sarelius IH, Remote arteriolar dilations in response to muscle contraction under capillaries. Am J Physiol Heart Circ Physiol 278: H1916-1923, 2000.

29. Cohen KD, Sarelius IH, Muscle contraction under capillaries in hamster muscle induces arteriolar dilatation via $\mathrm{K}_{\text {ATP }}$ channels and nitric oxide. J Physiol 539: 547555., 2002.

30. Klitzman B, Damon DN, Gorczynski RJ, Duling BR, Augmented tissue oxygen supply during striated muscle contraction in the hamster: Relative contributions of capillary recruitment, functional dilation, and reduced tissue $\mathrm{PO}_{2}$. Circ Res 51: 711$721,1982$. 
31. Hester RL, Duling BR, Red cell velocity during functional hyperemia: implications for rheology and oxygen transport. Am J Physiol Heart Circ Physiol 255: H236H244, 1988.

32. Welsh DG, Segal SS, Coactivation of resistance vessels and muscle fibers with acetylcholine release from motor nerves. Am J Physiol 273: H156-163, 1997.

33. Ellsworth ML et al., Erythrocytes: oxygen sensors and modulators of vascular tone. Physiology (Bethesda) 24: 107-116, 2009.

34. Crecelius AR, Luckasen GJ, Larson DG, Dinenno FA, $K_{\mathbb{I R}}$ channel activation contributes to onset and steady-state exercise hyperemia in humans. Am J Physiol Heart Circ Physiol 307: H782-H791, 2014.

35. Armstrong ML, Dua AK, Murrant CL, Potassium initiates vasodilatation induced by a single skeletal muscle contraction in hamster cremaster muscle. J Physiol 581: 841-852, 2007.

36. Pierzga JM, Segal SS, Spatial relationships between neuromuscular junctions and microvessels in hamster cremaster muscle. Microvasc Res 48: 50-67, 1994.

37. Kawashima K, Fujii T, Basic and clinical aspects of non-neuronal acetylcholine: overview of non-neuronal cholinergic systems and their biological significance. J Pharmacol Sci 106: 167-173, 2008.

38. Howitt $L$ et al., Spreading vasodilatation in the murine microcirculation: attenuation by oxidative stress-induced change in electromechanical coupling. J Physiol 591: 2157-2173, 2013.

39. Tallini $\mathrm{Y}$ et al., Propagated endothelial $\mathrm{Ca}^{2+}$ waves and arteriolar dilation in vivo. Measurements in Cx40 ${ }^{\mathrm{BAC}}$ GCaMP2 transgenic mice. Circ Res 101: 1300-1309, 2007.

40. Duza $\mathrm{T}$, Sarelius $\mathrm{IH}$, Conducted dilations initiated by purines in arterioles are endothelium dependent and require endothelial $\mathrm{Ca}^{2+}$. Am J Physiol Heart Circ Physiol 285: H26-37, 2003. 
41. Bagher $P$ et al., Low intravascular pressure activates endothelial cell TRPV4 channels, local $\mathrm{Ca}^{2+}$ events, and $\mathrm{IK}_{\mathrm{Ca}}$ channels, reducing arteriolar tone. Proc Natl Acad Sci USA 109: 18174-18179, 2012.

42. Yang $\mathrm{Y}$ et al., Heterogeneity in function of small artery smooth muscle $\mathrm{BK}_{\mathrm{Ca}}$ : involvement of the $\beta 1$-subunit. J Physiol 587: 3025-3044, 2009.

43. Jackson WF, Blair $\mathrm{KL}$, Characterization and function of $\mathrm{Ca}^{2+}$-activated $\mathrm{K}^{+}$channels in arteriolar muscle cells. Am J Physiol Heart Circ Physiol 274: H27-H34, 1998.

44. Potocnik SJ et al., Endothelium-dependent vasodilation in myogenically active mouse skeletal muscle arterioles: Role of EDH and $\mathrm{K}^{+}$channels. Microcirculation 16: 377-390, 2009.

45. Wölfle SE, Schmidt VJ, Hoyer J, Köhler R, de Wit C, Prominent role of KCa3.1 in endothelium-derived hyperpolarizing factor-type dilations and conducted responses in the microcirculation in vivo. Cardiovasc Res 82: 476-483, 2009.

46. de Wit C, Different pathways with distinct properties conduct dilations in the microcirculation in vivo. Cardiovasc Res 85: 604-613, 2010.

47. Ellsworth ML, Ellis CG, Sprague RS, Role of erythrocyte-released ATP in the regulation of microvascular oxygen supply in skeletal muscle. Acta Physiol (Oxf), 2015.

48. Burnstock G, Ralevic V, Purinergic signaling and blood vessels in health and disease. Pharmacol Rev 66: 102-192, 2014.

49. McCullough WT, Collins DM, Ellsworth ML, Arteriolar responses to extracellular ATP in striated muscle. Am J Physiol Heart Circ Physiol 272: H1886-1891, 1997.

50. Ross GA, Mihok ML, Murrant CL, Extracellular adenosine initiates rapid arteriolar vasodilation induced by a single skeletal muscle contraction in hamster cremaster muscle. Acta Physiol (Oxf) 208: 74-87, 2013.

51. Mortensen SP, Saltin B, Regulation of the skeletal muscle blood flow in humans. Exp Physiol 99: 1552-1558, 2014. 
52. Lim To WK, Kumar P, Marshall JM, Hypoxia is an effective stimulus for vesicular release of ATP from human umbilical vein endothelial cells. Placenta 36: 759-766, 2015.

53. Bodin P, Bailey D, Burnstock G, Increased flow-induced ATP release from isolated vascular endothelial cells but not smooth muscle cells. Br J Pharmacol 103: 12031205, 1991.

54. Burns WR, Cohen KD, Jackson WF, $\mathrm{K}^{+}$-induced dilation of hamster cremasteric arterioles involves both the $\mathrm{Na}^{+} / \mathrm{K}^{+}$-ATPase and inward-rectifier $\mathrm{K}^{+}$channels. Microcirc 11: 279-293, 2004.

55. Hungerford JE, Sessa WC, Segal SS, Vasomotor control in arterioles of the mouse cremaster muscle. FASEB J 14: 197-207, 2000.

56. Budel S, Bartlett IS, Segal SS, Homocellular conduction along endothelium and smooth muscle of arterioles in hamster cheek pouch: unmasking an NO wave. Circ Res 93: 61-68, 2003.

57. Rivers RJ, Hein TW, Zhang C, Kuo L, Activation of barium-sensitive inward rectifier potassium channels mediates remote dilation of coronary arterioles. Circulation 104: 1749-1753, 2001.

58. Quayle JM, Dart C, Standen NB, The properties and distribution of inward rectifier potassium currents in pig coronary arterial smooth muscle. J Physiol 494: 715-726, 1996.

59. Jantzi MC et al., Inward rectifying potassium channels facilitate cell-to-cell communication in hamster retractor muscle feed arteries. Am J Physiol Heart Circ Physiol 291: H1319-1328, 2006.

60. Figueroa XF et al., Central role of connexin40 in the propagation of electrically activated vasodilation in mouse cremasteric arterioles in vivo. Circ Res 92: 793800., 2003.

61. Jackson WF, Hypoxia does not activate ATP-sensitive $\mathrm{K}^{+}$channels in arteriolar muscle cells. Microcirc 7: 137-145, 2000. 
62. Garland CJ, Yarova P, Jiménez-Altayó F, Dora KA, Vascular hyperpolarization to $\beta$ adrenoceptor agonists evokes spreading dilatation in rat isolated mesenteric arteries. Br J Pharmacol 164: 913-921, 2011.

63. Kawashima K, Fujii T, Moriwaki Y, Misawa H, Horiguchi K, Reconciling neuronally and nonneuronally derived acetylcholine in the regulation of immune function. Ann N Y Acad Sci 1261: 7-17, 2012.

64. Bligh J, The level of free choline in plasma. J Physiol 117: 234-240, 1952.

65. Rosenmeier JB, Hansen J, Gonzalez-Alonso J, Circulating ATP-induced vasodilatation overrides sympathetic vasoconstrictor activity in human skeletal muscle. J Physiol 558: 351-365, 2004.

66. Vollestad NK, Hallen J, Sejersted OM, Effect of exercise intensity on potassium balance in muscle and blood of man. J Physiol 475: 359-368, 1994.

67. Crecelius AR, Kirby BS, Luckasen GJ, Larson DG, Dinenno FA, ATP-mediated vasodilatation occurs via activation of inwardly rectifying potassium channels in humans. J Physiol 590: 5349-5359, 2012.

68. Inokuchi $\mathrm{K}$ et al., Role of endothelium-derived hyperpolarizing factor in human forearm circulation. Hypertension 42: 919-924, 2003.

69. Feher A, Broskova Z, Bagi Z, Age-related impairment of conducted dilation in human coronary arterioles. Am J Physiol Heart Circ Physiol 306: H1595-1601, 2014.

70. Borysova L, Wray S, Eisner DA, Burdyga T, How calcium signals in myocytes and pericytes are integrated across in situ microvascular networks and control microvascular tone. Cell Calcium 54: 163-174, 2013. 


\section{Figures and Legends}
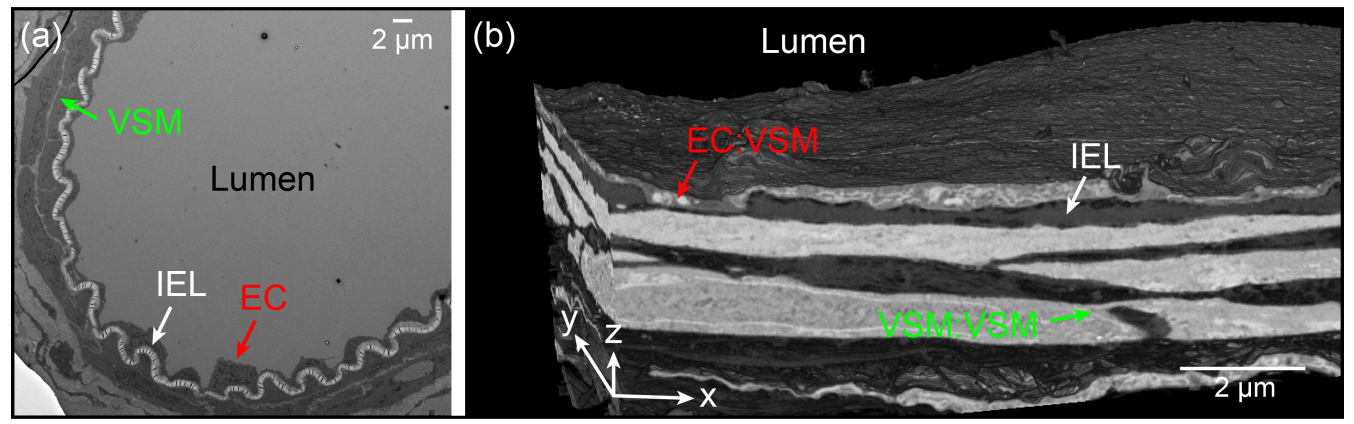

Figure 1. Structure of the arteriolar wall. Isolated, cannulated rat skeletal muscle arteriole with myogenic tone fixed at an intraluminal pressure of $75 \mathrm{mmHg}$ and imaged by electron microscopy ( $a$ : TEM; b: 3D SEM) indicating the orientation of and contacts between cells. VSM, smooth muscle cell; EC, endothelial cell; IEL, internal elastic lamina. 


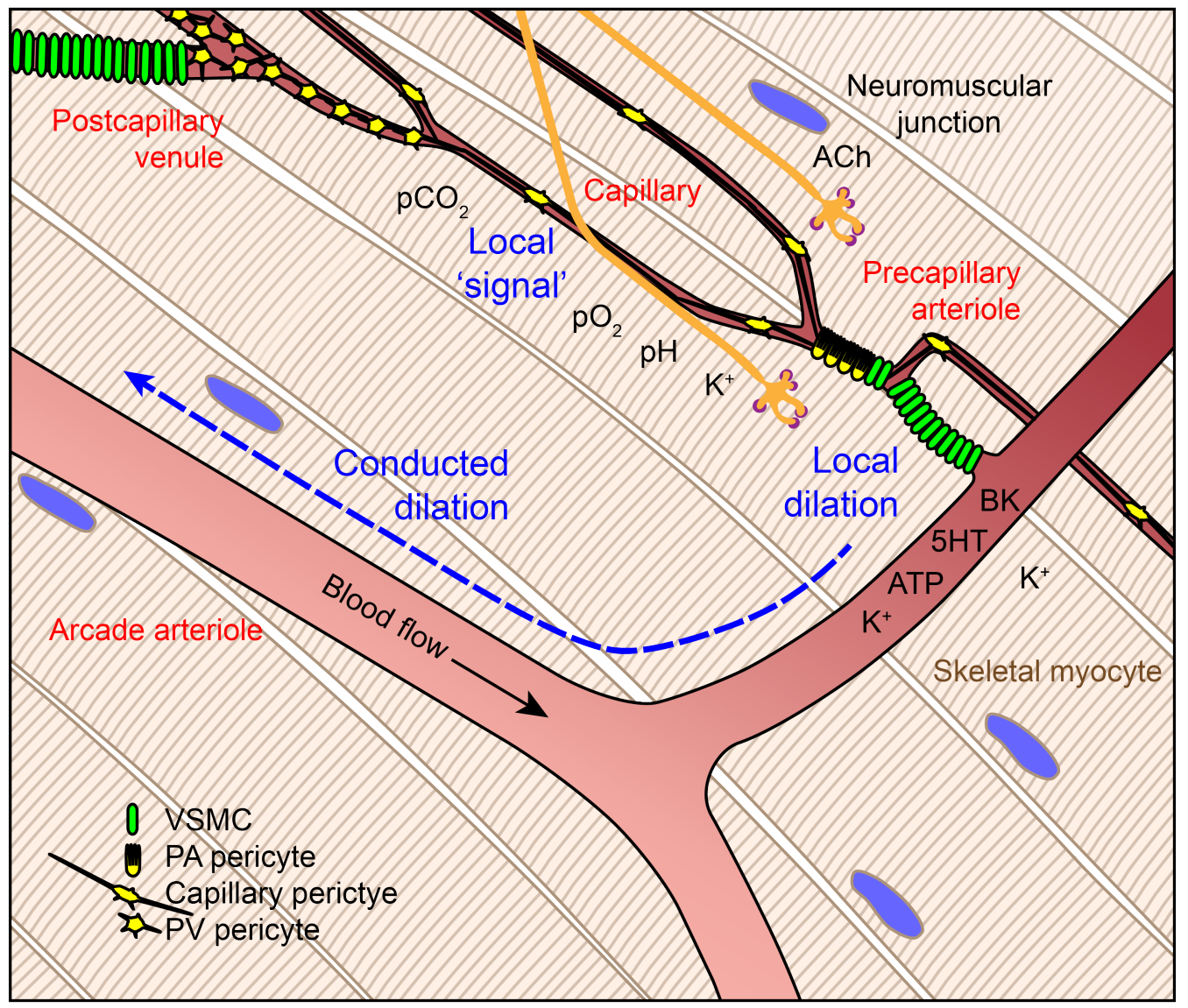

Figure 2. Factors influencing blood flow in skeletal muscle. Schematic depicting the agents known to influence blood flow within skeletal muscle. This review is limited to known actions at the arterial circulation, but recent evidence supports roles for pericytes, capillaries and post-capillary venules [70]. If the local stimulus leads to opening either SMC or EC K ${ }^{+}$channels, conducted dilation may be observed. $5 \mathrm{HT}, 5$ hydroxytryptamine; BK, bradykinin. 